\title{
O cavaleiro inexistente: um dilema para a psicologia?
}

\author{
Marcela Marjori Massolini Laureano ${ }^{1}$ \\ Humberto Barbosa Alcântara²
}

\section{Resumo}

O Cavaleiro Inexistente, de Ítalo Calvino, serve de mote ao questionamento acerca da subjetividade, tão cara à Psicologia. Descartes inaugurou a modernidade apartando em definitivo corpo e alma; de certa forma, uma reedição do dilema platônico. Sob o prisma da subjetividade, entretanto, nada é tão dicotomicamente separado, e corpo e alma hão de se completar nessa construção. A Psicologia persegue dissecar o subjetivo com a objetividade que o método cartesiano impôs ao científico; mas algo parece sempre escapar da observação. Esse inconsciente que escapa retorna no sintoma e desafia a Psicologia em relances fugidios, completos na incompletude dos mecanismos de deslocamento e condensação. Não há corpo sem alma, não há uma subjetividade assepticamente objetiva e O Cavaleiro Inexistente, se é pura razão, não se sente completo sem um corpo que mostre o ser humano que nele habita. O grande dilema da Psicologia é descobrir se é possível criar caminhos que levem ao entendimento do entrelace do corpo e da mente.

Palavras-chave: Subjetividade. Sintoma. Inconsciente. Mente. Modernidade.

\section{Introdução}

Seria o homem um ser de infinitas possibilidades? O que, em última análise, impõe a cada um de nós, nossos caminhos, nossas escolhas? Uma dúvida socrática, às vezes, uma "escolha de sofia" ${ }^{3}$, tantas outras. O que interessa no projeto da

1 Psicóloga (UNESP-2001), Doutora em Ciências (área: Psicologia) na FFCLRP/USP com estágio PDEE na Université Paris 3 - Sorbonne-Nouvelle (Doutorado direto concluído em 2008); Professora do Centro Universitário de Brasília (UniCEUB/FACES/Psicologia).

2 Granduando em Psicologia no UniCEUB.

3 Referência ao filme (1999, diretor: Erik Gustavson, produtor: Jostein Gaarder) baseado no romance de William Clark Styron, em que uma mãe é obrigada por um soldado nazista a escolher entre os dois filhos qual deveria ser encaminhado para a morte. 
modernidade é que o homem assume não ter uma posição natural definida; isso significa que ele escolhe livremente e, se nada é, pode ser qualquer coisa. Assim, escolhemos, e essa escolha nos faz caminhar.

Rolnik (1999) ressalta tal aspecto ao indicar que o homem contemporâneo vive uma intensificação da experiência de ruptura e, ao final, é a relação do homem com o caos o que está em jogo. A infinitude das variações é inquietante e, simplesmente, tudo se pode esperar, legitimamente, de um mundo infinitamente diverso e surpreendente (FIGUEIREDO, 1999).

O Cavaleiro Inexistente, do italiano Italo Calvino, um soldado das hostes do Imperador Carlos Magno, desafia a imaginação do leitor. Ele, uma armadura sem corpo alçada à distinção de Cavaleiro por sua bravura na defesa de certa donzela, confronta-nos em angústias e inquietações. Ele, a pura razão, parece não se bastar na busca de sensações que somente pelo corpo há que se ter acesso. Ele, a perfeição imaculada, à busca dos sentimentos imperfeitos que o façam se sentir um verdadeiro ser humano.

O Cavaleiro Inexistente é uma parábola que nos permite repensar paradigmas da modernidade. Por meio dela, pretende-se questionar as soluções da Psicologia para o tratamento das subjetividades, as quais vivem de uma característica definidora que é a singularidade. À Psicologia resta o dilema de construir, com objetividade científica, modelos para enfrentamento da subjetividade. Uma questão - ao que parece - ainda em aberto: será viável?

\section{Desenvolvimento}

Platão inaugurou um dualismo ontológico há mais de dois mil anos e, desde então, "ao inventar o mundo das ideias, espalhou a discórdia entre os filósofos, que nunca mais chegaram a um consenso sobre o que existe ou não" (TEIXEIRA, 2003, p. 18). Mente e cérebro, corpo e alma, razão e sentido, dicotomias colocadas sobre o humano, escolhas que tantos autores definiram. Mas, cuidado! É imperioso observar que, nem sempre, os conceitos se equivalem e a discussão, que pode parecer 
em torno do mesmo tema, possui sutilezas que lhe deixam vieses incontornáveis (FIGUEIREDO, 1995).

Platão afirmava que a alma é a via régia para o mundo de ideias, entretanto, o corpo também possuía a via dos sentidos e que deveria ser trilhada. Vale dizer, não há contraposição entre sentido e razão, ambos são o lastro de arenas diferentes, não opostas. Dessa forma, “[a purificação] é apartar o mais possível a alma do corpo, habituá-la a evitá-lo, a concentrar-se sobre si mesma por um refluxo vindo de todos os pontos do corpo" (PLATÃO, 1979, p. 69). O corpo, pois, reflui sobre a alma; esta nele também se abebera.

Assim, quando a modernidade viu surgir o cogito cartesiano, em torno do qual tanto debate se trava, não se pode afirmar ser uma reedição da dicotomia platônica. O método chega para afirmar a mente como a única substância absoluta do saber. O método inaugurado por Descartes semeia a eterna dúvida e desconfiança de toda a transitoriedade que é apanágio dos sentidos.

Mas uma alma, se a assimilamos à mente moderna, não vive sem o corpo, sem um cérebro, sem uma estrutura de sentidos: "Mesmo aquele seu miserável corpo [aqui se fala do morcego] impreciso entre o rato e o volátil era sempre algo de tangível e seguro, alguma coisa que poderia se sacudir pelos ares de boca aberta" (CALVINO, 2001, p. 16), reclama Agilulfo, o Cavaleiro Inexistente. A narrativa de Calvino marca a inevitável possibilidade de que as fronteiras entre corpo e mente não sejam absolutamente estanques e sua ductilidade se deixa surpreender à medida que a releitura se faça do papel da razão, em seu possível contraponto aos sentidos.

Agilulfo Emo Bertrandino dos Guildiverni e dos Altri de Corbentraz e Sura, armado cavaleiro de Selimpia Citeriore e Fez, com toda a pompa e circunstância e a assepsia que somente a razão pode dar, é uma voz metálica que emerge de uma armadura imaculadamente branca entre um exército de homens sujos e mal cheirosos. Por ser essa razão pura, impecável e impenetrável "não era possível decompô-lo em pedaços, desmembrá-lo: era e permanecia em cada momento do dia e da noite Agilulfo Emo Bertrandino” etc; (CALVINO, 2001, p. 15). 
Ser somente razão dá-nos a certeza da verdade, garante Descartes. E nos ensina a chegar a tal verdade, indene de toda dúvida:

[...] mas isso antes testemunha que o poder de bem julgar e distinguir o verdadeiro do falso, que é propriamente o que se denomina o bom senso ou a razão, é naturalmente igual em todos os homens; e, destarte, que a diversidade de nossas opiniões não provém do fato de serem uns mais racionais do que outros, mas somente de conduzirmos nossos pensamentos por vias diversas e não considerarmos as mesmas coisas (DESCARTES, 1979, p. 29).

E arremata: "Pois não é suficiente ter o espírito bom, o principal é aplicá-lo bem” (DESCARTES, 1979, p. 29). Em outras palavras, é uma questão de método. E fácil assim seria, se a razão não estivesse imbricada ao corpo em uma subjetividade tão sui generis e irrepetível. Singularidade que escapa de qualquer prognóstico generalizador; sujeito das liberdades possíveis, o fundamento autofundante de um mundo que passa a ser um exclusivo e puro objeto de conhecimento e controle (FIGUEIREDO, 1995), assim quer um dos projetos da modernidade para a subjetividade.

Calvino parece nos lembrar de que a pura razão, por si mesma, é insustentável, uma vez que o Cavaleiro Inexistente até possuía a armadura mais linda e imaculada de todo o campo, dele inseparável, mas "sentia que incomodava a todos e gostaria de fazer algo para restabelecer uma relação qualquer com o próximo [...] dar ordens, dizer impropérios dignos de um caporal ou provocar e dizer palavrões como se faz entre companheiros de pensão" (CALVINO, 2001, p. 16). A razão parece não se bastar. Mas, do método espera-se "uma certeza subjetiva como critério de verdade e como garantia de conhecimento" (FIGUEIREDO, 1995, p. 138). Nesse sentido, o humano deve tornar-se objetivo, para ser universal e poder aplicar-se incontestável e generalizadamente.

Sobre esse aporte epistemológico, as ciências médicas vão se desenvolver e, a reboque delas, também a Psicologia. A Psiquiatria, desde Kraepelin, busca critérios médicos classificatórios para combater tantos males do corpo. Em certa medida, descobre-se que também há males que cercam a mente e sobre essa desrazão é preciso que a ciência se pronuncie. À medida que o mal deixa de serem corporal- 
mente palpáveis, muitos outros fatores passam a serem possibilidades de influência. Psíquicos, sociais, familiares, econômicos, intangíveis em sua interação, todos desafiam o corpo de conhecimentos científicos e suas explicações absolutamente racionais, sustentadas pelo método.

A ironia do Cavaleiro Inexistente é notar sua inconformidade, sua necessidade disfarçada por uma vida com substância na realidade: ele precisa da alteridade do outro para dar ordens, para manter seu título pela defesa de Sofrônia. E é pela voz de Carlos Magno que Calvino nos conclama a perceber que não se há de separar corpo e espírito "Aqui temos um súdito que existe, mas não tem consciência disso [Gurdulu] e aquele meu paladino que tem consciência de existir, mas de fato não existe. Fazem uma bela dupla, é o que lhes digo!" (CALVINO, 2001, p. 29).

Não há método que possa separar o sujeito, pois:

[...] a cisão, ao mesmo tempo em que opera excluindo, opera instituindo uma "outra realidade" sob a forma negativa do subterrâneo que, de uma maneira ou de outra, forçará a passagem e invadirá com seus rumores inarticulados o mundo das representações claras e distintas (FIGUEIREDO, 1995, p. 141)

Esse subterrâneo que retorna é uma voz inconsciente recalcada, mandada dormir antes mesmo de despontar na consciência. Mas a energia do inconsciente é uma força que não dorme; indômito, o recalcado se insinua, quer-se mostrar ali, onde a consciência descansa. Pois na economia psíquica, à energia deve ser dada vazão e assim o inconsciente busca artimanhas, ardis por meio dos quais um espaço se forma e, pelo sintoma, ocorre a descarga de energia.

"Na vida psíquica, com efeito, a tensão nunca se esgota. Estamos, enquanto vivemos, sob constante tensão" (NASIO, 1999, p. 18). As representações de coisa que habitam o sistema inconsciente obedecem ao princípio do prazer-desprazer e a sua missão é escoar a tensão o mais rapidamente possível e, por consequência, alcançar o prazer absoluto. Investidas de energia a descarregar, tais representações vão se rearranjando por deslocamentos e condensações, transformando-se sempre em busca de vencer a barreira do recalque erigida pelos sistemas pré-consciente e 
consciente. Esses, funcionando pelo princípio de realidade buscam escoar a energia lentamente, em busca de um prazer moderado, condizente com a realidade com a qual eles se deparam face a face.

Nesse embate de forças nas instâncias psíquicas, a energia que a barreira do recalque consegue deter, retorna e realimenta o sistema inconsciente e o mantém em ebulição constante. Uma economia psíquica que se erigisse a partir da descarga completa e total da energia, venceria a barreira do recalque e deixaria o sujeito face ao perigo de um gozo total e completo, um prazer absoluto impossível de alcançar (NASIO, 1999).

Em outra vertente, a barreira do recalque pode ser suficiente para canalizar a energia em atividades intelectuais que proporcionam ao sujeito o prazer moderado e mediado pelas exigências do princípio da realidade. Por fim, a energia psíquica pode vencer a barreira do recalque, agora alcançando um prazer parcial e substitutivo, evidenciado nas formações do inconsciente: chistes, atos falhos, sintomas (NASIO, 1999).

Em suas “Conferências”, Freud preleciona a necessidade do sentido do sintoma ser inconsciente para que ele, sintoma, possa surgir, uma vez que "tão logo os processos inconscientes pertinentes se tenham tornado conscientes, o sintoma deve desaparecer" (FREUD, 2006, p. 289). "Os sintomas têm um sentido e se relacionam com a experiência do paciente" (FREUD, 2006, p. 265). Essa experiência, que envolve uma energia que as instâncias psíquicas conscientes não conseguem suportar ou manipular, vem transvestida e assim a ideia original é deslocada para longe da conformação original. No sintoma, um recalque que não dorme se disfarça para exibir-se por inteiro; uma esfinge que mostra dentes e entranhas: "decifra-me ou te devoro".

Sintoma que a psicopatologia tenta compilar, classificar, listar, definir. Ocorre que, não raras, ou mais bem dito, na maioria das vezes, o singular escapa a qualquer previsão, pelo só fato de sua singularidade. O que deve fazer a Psicologia, cujo objeto pretende ir aonde o sujeito possa estar? Reduzir-se aos sintomas tão bem articulados das classificações nosográficas ou buscar uma dinâmica que vai 
mais além, diz da própria singularidade, a qual qualquer conjunto de sintomas dificilmente será capaz de captar?

A história de Calvino traz personagens interessantes: um cavaleiro que é só razão, cujo escudeiro é a própria desrazão. Outros que seguem angustiados em busca de sentido para suas vidas e um, em especial, que parece ser um corpo que dará completude àquela armadura vazia e impenetrável. É Rambaldo, em suas dúvidas e inquietações, tão comezinhas, exatamente por humanas:

Ainda ontem, vendo baixar o sol, [Rambaldo] se perguntava: "Que será de mim no pôr-do-sol de amanhã? Terei superado a prova? Terei a confirmação de ser um homem? De deixar marcas caminhando pela terra?”. E, pronto, este era o primeiro pôr-do-sol daquela manhã, e as primeiras provas, vencidas, já não contavam mais nada, e a nova prova era inesperada e difícil, e a confirmação só podia estar lá. Nesse estado de incerteza, Rambaldo gostaria de trocar confidências com o cavaleiro da armadura branca, como se fosse o único capaz de compreendê-lo, nem ele mesmo saberia dizer por quê (CALVINO, 2001, p. 48).

O desfecho, sob esse ponto de vista, não parece tão absurdo assim. Ao final, um corpo se reencontra com a razão, numa unidade indelegável:

Não sou Agilulfo, Majestade! - A celada se ergue e surge o rosto de Rambaldo. - Do cavalheiro dos Guildiverni só restou a armadura branca e este papel que me garante sua posse. Não vejo a hora de entrar em combate! [...]. Mas o que também quero é apenas ser alguém que sabe o que deseja! (CALVINO, 2001, p. 126/127).

\section{Conclusão}

Esse é um desafio para a Psicologia: perceber que somos sujeitos, que gostaríamos de ser alguém que saiba o que deseja. No caminhar onde nos construímos, muitas batalhas são travadas. Às vezes, a armadura se separa do corpo e vamos nos recompondo em delírios; em outras, conseguimos alcançar um desenvolvimento mais pleno, sempre com as marcas que forjamos pelo caminho. Se somos sujeitos desejantes, mesmo sem saber, buscamos o que nos falta. Mas o 
mundo não espera um sujeito, uma singularidade e, dificilmente haverá perdão para aquele que destoa.

O desafio da Psicologia é construir caminhos, a despeito da epistemologia que se impõe; descobrir o sujeito no sintoma, ainda que o uso de classificações seja imperativo; reconfigurar, quem sabe, seu objeto, ampliando o conceito de sujeito de modo a abarcar sua indecifrável subjetividade, um eterno retorno, que sempre será renovado, como nos atesta Bradamente/Irmã Teodora:

[...] A página tem o seu bem só quando é virada e há vida por trás que impulsiona e desordena todas as folhas do livro. [...] O capítulo que começamos e ainda não sabemos que história vamos contar é como a encruzilhada que superamos [...] e não sabemos se nos vai colocar diante de um dragão, um exército bárbaro, uma ilha encantada, um novo amor. Corro, Rambaldo. [...] sabem que depois das batalhas, abraços e enganos retorno sempre a este claustro. Mas desta vez será diferente... Será ... (CALVINO, 2001, p. 13248).

Esse o questionamento à Psicologia, sempre renovado: lidar com as múltiplas e multifacetadas possibilidades do humano.

Será que a Psicologia conseguirá? [...] Será? [...]

\section{The nonexistent knight: a dilemma for the psychology?}

\section{Abstract}

“The Nonexistent Knight", by Italo Calvino, is the start point to discuss the way the modernity has constructed the human being. Descartes is the modern mentor of the dilemma between body and soul, since Plato had proposed the Ideas world. But body and mind can't leave without each other. It's not possible to completely separate them objectively; something is always missing. And that are the unconscious psychic processes, which return throughout the symptom. Psychology must understand them if it intends to discuss subjective quality. It's necessary, 
though, to pay carefully attention to the little signs from symptoms, since they are joined through unconscious mechanisms. There is no body without a soul. If The Nonexistent Knight is a pure reason, he won't be comfortable until he expresses his self throughout a real body. The dilemma that Psychology deals with is to face the challenge to discover the possible ways that ends with the understanding of the join between body and mind.

Keywords: Subjective quality. Symptom. Inconsciousness. Mind. Modernity.

\section{Referências}

CALVINO, I. O cavaleiro inexistente. São Paulo: Companhia das Letras, 2001.

DESCARTES, R. O discurso do método. São Paulo: Abril Cultural, 1979.

FIGUEIREDO, L. C. O silêncio e as falas do corpo. In: MODOS de subjetivação no Brasil. São Paulo: Escuta, 1995.

FIGUEIREDO, L. C. A invenção do psicólogo. São Paulo: Escuta, 1999.

FREUD, S. Conferências introdutórias sobre psicanálise: conferência XVIII: fixação em traumas: o inconsciente. Rio de Janeiro: Imago, 2006. v. 15.

NASIO, J. -D. O prazer de ler Freud. Rio de Janeiro: J. Zahar, 1999.

PLATÃO. Fédon. In: Diálogos. São Paulo: Abril Cultural, 1979. 264p.

ROLNIK, S. A invenção do psicólogo. São Paulo: Escuta, 1999.

TEIXEIRA. J. F. Mente, cérebro e cognição. Petrópolis: Vozes, 2003. 
Para publicar na revista Universitas: Ciências da Saúde, acesse o endereço eletrônico www.publicacoesacademicas.uniceub.br. Observe as normas de publicação, para facilitar e agilizar o trabalho de edição. 